\title{
El control judicial de la discrecionalidad en la asignación de pautas publicitarias del Estado en la Argentina' ${ }^{1}$
}

\begin{abstract}
Agustín A. M. García Sanz ${ }^{2}$
El autor es abogado de la Universidad de Buenos Aires, casa de estudios en la que ejerce la docencia. También es profesor titular de Regulación Económica I de la Carrera de Especialización en Derecho Administrativo de la Universidad Católica de La Plata, bajo la dirección de Rodolfo C. Barra. Es sub-director de la Revista Res Publica Argentina, dirigida por Agustín Gordillo, en cuya cátedra se formó. Profesionalmente, ha trabajado en distintos cargos en el sector público, ha sido abogado del Estudio M \& M Bomchil, en el equipo de Guido S. Tawil y, en la actualidad, es asociado del Estudio Marval, O'Farrell \& Mairal, firma en la que trabaja con el Héctor Mairal.
\end{abstract}

Resumen: El artículo analiza la cuestión del control judicial de la discrecionalidad en la asignación de pautas publicitarias del Estado en la República Argentina, a partir del estudio de una decisión de la Sala IV de la Cámara Nacional de Apelaciones en lo Contencioso Administrativo Federal.

Palabras clave: Control judicial. Discrecionalidad. Asignación de pautas publicitarias. República Argentina.

Sumario: 1 Las razones para el festejo actual - 2 Las preguntas que buscan respuesta - 2.1 ¿De qué hablamos? - 2.2 ¿Qué puede hacer el Estado en términos de publicidad? Cuestiones de finalidad y legalidad presupuestaria - 2.3 ¿Cuáles son los límites para la definición del contenido de la publicidad oficial? - 2.4 Los Tiempos: ¿Cuándo puede publicitar el Estado? - 2.5 Los modos: ¿es necesaria la publicidad que actualmente se realiza en todos los casos? - 2.6 Control de pautas y ejecución del gasto: ¿quién le pone el cascabel al gato? - 2.7 Contratación: ¿Cómo debe contratarse la publicidad? - 2.8 ¿Hace falta una norma? - 3 El rol de la Justicia ante la falta de un marco legal adecuado

El sistema republicano de gobierno adoptado por la Constitución nacional argentina (y necesariamente seguido por las provinciales) ${ }^{3}$ no admite que un funcionario del Estado, sea del Poder que fuere, pueda elegir discrecionalmente el destino de la pauta publicitaria oficial de acuerdo a las afinidades estéticas, políticas o ideológicas de los medios de comunicación a los que esa pauta puede ser asignada y mucho menos que esa asignación resulte de la decisión de beneficiar económicamente

\footnotetext{
El presente trabajo está basado en la ponencia presentada en las Jornadas de Derecho Administrativo de la Universidad Austral, Buenos Aires, Argentina, 2009, publicada en AA. VV. Cuestiones de Control de la Administración Pública. Administrativo, Legislativo y Judicial — Jornadas Organizadas por la Universidad Austral Facultad de Derecho, Buenos Aires, Ediciones Rap, 2010.

2 Deseo agradecer la colaboración de los Dres. Nicolás Diana, Santiago Carrillo, Nicolás Eliaschev y Marcos García Domínguez por sus aportes y comentarios durante la elaboración de este trabajo.

3 Habida cuenta que para la adopción de sus respectivas constituciones provinciales deben respetar la forma de gobierno adoptada por la Constitución nacional (cfr. artículos 5 y 123 de la Constitución Nacional).
} 
a un medio determinado en detrimento de otro. Ni siquiera lo admite la justicia penal, llamada a aplicar criterios mucho más restrictivos en su análisis de tipicidad. ${ }^{4}$ Es que, sencillamente, no se trata de premiar o castigar nada, mucho menos de hacer fomento: se trata de dar a publicidad la acción de gobierno por los medios más eficaces disponibles, de modo que ella pueda ser conocida, escrutada y evaluada por los ciudadanos. ${ }^{5}$

Recientemente, una decisión de la Sala IV de la Cámara Nacional de Apelaciones en lo Contencioso Administrativo Federal avanzó con determinación hacia la demarcación de un nuevo límite para la discrecionalidad del gasto en materia de publicidad oficial. Todavía debemos esperar una definición de la Corte Suprema de Justicia de la Nación que viene en camino, ${ }^{6}$ pero algunas señales recientes ${ }^{7}$ permiten soñar con una confirmación del sano criterio fijado por la Sala IV.

Pero el festejo por este fallo debe dejar lugar para las preguntas y, con ellas, para la definición de los debates todavía por venir en materia de control de la pauta publicitaria del Estado. La llamativa ausencia de un marco normativo que regule y transparente la cuestión en el plano federal, sumada a situaciones similares en el plano provincial y de la Ciudad de Buenos Aires, ${ }^{8}$ reclaman de nuestros Jueces un acabado control judicial. A tratar estas cuestiones dedicaré este trabajo.

\section{Las razones para el festejo actual}

La Cámara ha llegado a la decisión que marca el punto de partida de este trabajo asumiendo que, si bien ningún medio tiene un derecho intrínseco a recibir pauta publicitaria del Estado, cuando esa pauta existe

\footnotetext{
4 La Cámara Nacional de Apelaciones en lo Criminal y Correccional Federal, Sala II, decidió el 17-XI-09, en los autos "Albistur, Enrique y otra", revocar el sobreseimiento de primera instancia en una causa por presuntas irregularidades en la asignación de la pauta publicitaria oficial. Albistur, el procesado, era Secretario de Medios de Comunicación de la Nación a cargo de la distribución de la pauta oficial. Sostuvo la Cámara que restaba determinar cuál había sido la facturación de las empresas investigadas, si existió equivalencia o desproporción con las pautas oficiales asignadas a otras empresas del mismo rubro, y de qué organismo público provinieron las solicitudes que finalmente se otorgaron a aquéllas.

5 En palabras de la Sala IV, "[s]i bien esa doctrina está referida a la actividad normativa del Estado como una necesidad básica en el fortalecimiento de la seguridad jurídica, fundamento de un racional comportamiento en los negocios y en las relaciones personales, también lo está como una necesidad de la ciudadanía de conocer lo realizado por el gobierno permitiendo un debido juzgamiento al momento de ser sometido la permanencia en el poder del grupo gobernante" (Cámara Nacional de Apelaciones en lo Contencioso Administrativo Federal, Sala IV, in re "Editorial Perfil S.A. y otro v. Estado Nacional - Jefatura de Gabinete de Ministros - Secretaría de Medios de Comunicación", 10-II-09).

6 El 24 de febrero de 2009 la decisión de la Cámara fue recurrida por el Estado Nacional. El día 12-V-09 las actuaciones fueron remitidas a la Corte. Un claro pronunciamiento de la Corte Suprema a este respecto dará a la cuestión el final que se merece.

7 Ver Fallos 330:3908 y 331:2893, recaídos en las causas "Editorial Río Negro c. Provincia de Neuquén" y "Radiodifusora Pampeana S.A. c. Provincia de La Pampa", respectivamente.

8 Entre las que cabe mencionar la judicializada discusión en las provincias de Neuquén y La Pampa o los debates en torno del crecimiento del gasto en publicidad del Gobierno de la Ciudad de Buenos Aires.
} 
y es distribuida, no puede serlo en modo irrazonable y desatendiendo el principio de igualdad. Es que, si ello ocurriera, se estaría afectando concomitantemente tanto la libertad de prensa y expresión ${ }^{9}$ como el acceso a la información pública por parte de la ciudadanía para poder ejercer con conciencia sus derechos políticos.

En efecto, siguiendo la doctrina de la Corte, ${ }^{10}$ la Cámara entendió que el art. 16 de la Constitución Nacional ${ }^{11}$ supone que no pueden establecerse excepciones o privilegios que excluyan a unos de lo que se concede a otros enidénticas circunstancias, masnoimpidequelalegislación contempleenforma diferente situaciones que considera distintas, cuando la discriminación no sea arbitrarianirespondaaunpropósitodehostilidadcontradeterminadosindividuos o clases de personas, ni encierre indebido favor o privilegio personal o de grupo.

Luego de dar por probada la intencionalidad discriminatoria por parte de la Secretaría de Medios de Comunicación y el hecho de que Perfil "tiene un nivel de emisión que implica una penetración importante en el público lector", la Cámara descartó el argumento estatal de que la editorial no dependa de esa pauta publicitaria para subsistir como atenuante $o$ eximente del yerro denunciado. ${ }^{12}$

Como puede advertirse, la Sala IV profundizó los criterios que en esta materia ha delineado la Corte en su nueva composición ${ }^{13}$ y lo ha hecho en el marco de un amparo. ${ }^{14}$ Razones sobran para el festejo en tiempo presente, por cuanto la forma y la cantidad de publicidad oficial asignada por el Estado ha quedado - así parece - finalmente sujeta a un control judicial suficiente. ¿Pero qué pasará con la sustancia?

\section{Las preguntas que buscan respuesta}

Estamos ante un inmejorable contexto para analizar las preguntas que se presentan de cara al futuro a la luz del estado actual de la

9 Reconocida en el art. 32 de la Constitución Nacional y en el art. 19 de la Declaración de los Derechos Humanos de la Organización de las Naciones Unidas.

10 Fallos 182:355.

11 Artículo 16, Constitución nacional: “La Nación Argentina no admite prerrogativas de sangre, ni de nacimiento: no hay en ella fueros personales ni títulos de nobleza. Todos sus habitantes son iguales ante la ley, y admisibles en los empleos sin otra condición que la idoneidad. La igualdad es la base del impuesto y de las cargas públicas."

12 En palabras de la Sala IV, si se exigiese que el Estado solvente "a aquellas publicaciones deficitarias, se estaría violando con mayor intensidad la libertad de expresión, en tanto le quitaría a la prensa la credibilidad necesaria respecto de la veracidad de lo que informa."

13 Justo es recordar que la Corte había sostenido criterios diferentes en el pasado, según los cuales el control judicial de la administración no podía alcanzar estos rincones del quehacer administrativo. Ver Fallos 320:1191.

14 Si bien la Cámara señala lo inusual del trámite por la abundancia probatoria, la decisión llegó de todos modos en el marco de este tipo de acción, herramienta idónea cuando lo que se pretende lograr es una rápida definición respecto del fondo del asunto planteado. Era necesario en este caso, para que la respuesta no llegara bajo una nueva administración. 
jurisprudencia en esta materia, tan sensible para el quehacer político y para la democracia en general. Según trataré de ilustrar en este trabajo, las respuestas preliminares a estas preguntas no hacen sino poner en evidencia la necesidad de un set de reglas claras, conocidas por todos, para la asignación de la pauta publicitaria pero, también, para la determinación de su sustancia y sus formas. Veamos.

\section{1 ¿De qué hablamos?}

El primer paso que me propongo es dar dimensión al problema. Es que al analizar un problema jurídico, la realidad tiene un impacto determinante, máxime cuando de ella depende la correcta apreciación de lo que sucede en tiempo presente, único modo de diseñar adecuadamente las herramientas para el tiempo futuro. Veamos, entonces, de qué hablamos.

Durante el año 2009, y sin considerar, por ejemplo, las sumas invertidas por empresas de las que es accionista, ${ }^{15}$ el Estado nacional argentino vino gastando a razón de más de un millón y medio de pesos diarios en publicidad oficial (R\$715.000, aproximadamente). ${ }^{16}$ Si bien con números globales más módicos, otro tanto puede decirse de lo que ocurre en la Ciudad de Buenos Aires, donde el año 2009 mostró un gasto acumulado que superaba los $\$ 100$ millones ( $R \$ 47$ millones) y un crecimiento del $88 \%$ en comparación con el año anterior. ${ }^{17}$

No estamos hablando, en definitiva, de unos pocos pesos destinados a poner en conocimiento de la población la fecha de cierre para la presentación del Impuesto a las Ganancias. Hablamos, por lejos, de un presupuesto que convierte al Estado en el mayor anunciante del país, con el poder que ello supone. Ahora bien: ¿Queremos que la administración tenga ese poder sobre los medios de comunicación de los que depende, en gran medida, la posibilidad de controlar - precisamente - la administración de la cosa pública? Mi respuesta a esta pregunta es ciertamente negativa.

\footnotetext{
${ }_{15}$ Mucho menos las que pudieran estar gastándose a través de recursos no discriminados en el Presupuesto.

${ }^{16}$ Ver el interesante informe de Ramón Indart en el Diario Perfil, accesible online en http://www.perfil.com/ contenidos/2009/08/12/noticia_0011.html.

17 Ver Sued, Gabriel, "Macri también aumentó el gasto en publicidad oficial", La Nación, 14-II-10 y "El gobierno de Macri también bate records", La Nación, 17-V-09. Ver de igual modo los informes de la Asociación por los Derechos Civiles al respecto, disponibles en www.acd.org.ar.
} 
2.2 ¿Qué puede hacer el Estado en términos de publicidad? Cuestiones de finalidad y legalidad presupuestaria

Corresponde, luego de asignar una magnitud concreta al problema, y tomando como punto de partida los criterios ya fijados por la jurisprudencia, empezar a formular las preguntas que permitan dirimir qué se puede y qué no se puede hacer en materia de publicidad con los dineros públicos.

La primera pregunta que surge es si es posible premiar la calidad periodística con la asignación de pauta publicitaria. Ciertamente no parece que sea posible, al menos, bajo ese rótulo. Y ello no sólo porque la frontera entre el premio a la calidad y el premio a la afinidad con quien asigna la pauta es, en un contexto de discrecionalidad, casi invisible, sino porque los fondos que el Congreso o las legislaturas autorizan al recaudador a apropiarse por vía de impuestos deben ser gastados con las finalidades aprobadas en la Ley de Presupuesto y no otras. $Y$, ciertamente, no encontramos las partidas destinada a la publicidad oficial entre las Transferencias que el sector público hace al privado. Tampoco vemos que esos fondos y su asignación, si es que de dar premios se trata, estén sujetos a reglamentos o mecanismos transparentes que permitan discernir qué es exactamente lo que se está premiando en cada caso, para que todos podamos participar de la compulsa. Ni qué hablar de que encontremos actos debidamente motivados, como para - al menos - poder analizarlos y eventualmente cuestionarlos desde ese flanco.

Pero si no se puede premiar la calidad con estos fondos, ¿se puede, entonces, subsidiar la publicación de quienes no consiguen el favor suficiente del público como para subsistir por su cuenta? Esta pregunta, a la luz de la recientemente aprobada Ley de Servicios de Comunicación Audiovisual, es crucial. ${ }^{18}$ La Sala IV en el fallo comentado ha dicho con acierto que no.

Nuevamente, asumiendo por hipótesis que tal apoyo se diera por una decisión de política cultural, si es que tal decisión fuera

\footnotetext{
${ }^{18}$ El análisis de esta nueva Ley de Servicios de Comunicación Audiovisual merecería un trabajo en sí mismo, sin perjuicio de los muchos más ricos comentarios que podrán llegar a hacerse una vez que sea reglamentada y puesta en marcha a partir de actos de aplicación. Sin embargo, basta en este punto señalar que dicha norma no ha previsto (i) el modo en que se distribuirá la pauta publicitaria entre los licenciatarios, permisionarios y autorizados, (ii) ni la sustancia, formas o tiempos en que resulta admisible la publicidad oficial. Esta omisión ocurre en el marco de una norma que habilita al Estado, a través de un órgano dominado por la fuerza política preponderante del momento, a otorgar las nuevas licencias y autorizaciones a operadores (con o sin fines de lucro; estatales o privados) que, por los contenidos que ofrecerán, seguramente no podrían subsistir sin aportes de la publicidad oficial. En este contexto, la necesidad de establecer reglas claras respecto de qué puede publicitar el Estado y cómo debe asignarse la pauta publicitaria resulta imprescindible.
} 
constitucionalmente admisible, ${ }^{19}$ no podría hacerse desde el rubro publicidad, sino desde el rubro correspondiente a los subsidios. Y así sabremos todos que la revista tal, o el programa cual, está siendo subsidiado con fondos específicamente alocados con esa finalidad, previa aprobación global por el Congreso de las partidas necesarias y sujetando la decisión a una adecuada motivación en el caso concreto y no al simple reparto global en una planilla de la Agencia Nacional de Noticias de la República Argentina (Telam), ${ }^{20}$ encargada de la administración de la pauta oficial. Pero tampoco es esto lo que ocurre.

En definitiva, se utiliza la pauta publicitaria oficial para fines no previstos en la ley. Reconozco - no sin cierto pudor - que, en los tiempos que corren, parece un tanto anacrónico hacer un alegato desde las orillas del principio de legalidad en materia presupuestaria ${ }^{21}$ y del necesario respeto de la finalidad con que el órgano ha sido dotado de competencias. Pero de esto hablamos: el Estado no puede usar los fondos públicos para fines no previstos en la ley, mucho menos para fines ocultos detrás de la necesidad de dar a publicidad las acciones de gobierno. Es que el acto administrativo que así lo disponga estará insanablemente viciado en su causa, en su objeto, en su motivación y en su finalidad; ni qué hablar del procedimiento. $Y$ allí donde ese principio no se respete, habrá espacio para el más acabado control judicial.

Pero este estándar debe imperar aun en ausencia de reclamo de algún medio de comunicación por el trato discriminatorio que hayan sufrido en carne propia, por la consecuente afectación de la libertad de prensa, del derecho a igual trato bajo la ley, del de propiedad o de ejercer industria lícita. Porque bien puede ocurrir que todos los medios se sientan bien atendidos por la pauta oficial y que, sin embargo, se sigan usando fondos bajo el rótulo "publicidad" para fines que la exceden por completo. ¿Y qué hacer entonces? ¿Alcanza con responder que se trata de una decisión política exenta del escrutinio judicial o que el casus no queda configurado? Ciertamente no. También deben poder acceder a

\footnotetext{
19 Decisión que de todos modos entiendo ilegítima por ser contraria al juego armónico de los arts. 14, 16, 17, 32 y 43 de la Constitución Nacional.

${ }^{20}$ Y debería exigirse, en tal caso, que el apoyo sea comunicado en modo claro en la publicación o programa mismos, para que el público sepa de primera mano que ese programa subsiste gracias a los fondos públicos.

21 A la luz de la llamada Ley de Superpoderes (ley 26.124). Ver en este sentido Gelli, María Angélica, "De la delegación excepcional a la reglamentación delegativa. Acerca de la reforma a la ley de Administración Financiera", LL 2006-E, 868.
} 
esta tutela las $\mathrm{ONGs}^{22}$ y los particulares afectados no ya por los derechos de los medios de comunicación ya señalados, sino por las barreras que tal discriminación supone para el acceso de la ciudadanía a la información pública sin interferencias irrazonables o ilegítimas por parte del propio Estado..$^{23}$

2.3 ¿Cuáles son los límites para la definición del contenido de la publicidad oficial?

En el punto anterior asumí, sólo a los fines expositivos, que el contenido de la publicidad de la que estaba hablando era un dato de la realidad ya dado y que lo que cabía preguntar era únicamente con qué fines podía usarse la asignación de la pauta, sin entrar a indagar sobre la sustancia. Pero este punto, la sustancia, es tanto o más importante que el anterior.

No habrá dudas, volviendo al ejemplo que diera párrafos más arriba, de que la publicidad sobre la fecha de cierre de las presentaciones de declaraciones juradas del impuesto a las ganancias debería estar entre los contenidos admitidos bajo el rubro "publicidad oficial". Pero ¿qué sucede con publicar por los medios consignas sobre las bondades de un determinado proyecto de ley enviado por el Poder Ejecutivo al Congreso? ¿Es admisible que se utilice la pauta oficial para cuestionar con nombre y apellido las posturas asumidas por los Jueces en fallos que no dan la razón al gobierno de turno? ¿Es razonable que se sufrague con impuestos la publicidad que sirva para poner presión sobre una disputa parlamentaria sujeta a la regla de las mayorías políticas? ¿Por qué podría disponer el Poder Ejecutivo de esa herramienta y no la oposición, que debería afrontar semejante presión mediática únicamente con los fondos provenientes de las arcas sus respectivos partidos políticos? ¿Y qué ocurre con anuncios únicamente destinados a resaltar la figura presidencial?

Es fácil concluir, entonces, que la discusión sobre el contenido que razonablemente puede admitirse en este tipo de publicidad oficial se torna mucho más compleja. A poco que se abandona la idea de un simple llamado a licitación o la reproducción de la síntesis de un nuevo marco

${ }^{22}$ Es interesante la tarea de control que se viene realizando, por ejemplo, desde la Asociación por los Derechos Civiles en esta materia, con la publicación de informes cuanti-cualitativos sobre el gasto en publicidad. Ver en www.adc.org.ar.

${ }^{23}$ Ver en torno de la legitimación en este tipo de casos, Gambier. Beltrán, "El poder de los ciudadanos", disponible online en http://portal.redargentina.com/foros/el-poder-de-los-ciudadanos. 
normativo, es decir, en cuanto nos alejamos de la publicidad destinada a poner a disposición del público aquella información indispensable para que los derechos puedan ser ejercidos de manera eficaz, eficiente e informada, empezamos a caminar sobre un terreno menos firme. Tanto más patente se torna el problema al dimensionarlo: en la actualidad, sólo el $7 \%$ de la pauta oficial del Estado federal tiene que ver con dar a publicidad licitaciones, pago de haberes o información de este tipo. Mientras tanto, sumada la pauta destinada a la difusión de gestión, a los avisos institucionales y al laxo rubro de "políticas públicas", se llega a un $88 \%$ del gasto total. ${ }^{24}$

Podría alguien sostener que dar a conocer consignas a favor de un determinado proyecto de ley o confrontar con sectores particulares de la sociedad a través de los medios son actividades inescindibles de la administración de la cosa pública. Se podría ir más allá y afirmar que la legitimidad del voto determina, una vez cada cuatro años, quién tomará las riendas del Poder Ejecutivo y se decide también quién puede usar el aparato del Estado para dar la más amplia difusión a las ideas y valores votados por la mayoría o por la primera minoría. Me permito disentir con quien esto afirme.

Es que el sistema electoral y el de partidos políticos dan respuesta a esta cuestión, no el estándar de publicidad de los actos de gobierno. La lucha política en busca del apoyo de las mayorías, sea en plena campaña electoral a favor de un candidato o en los períodos entre elecciones para debates sobre temas puntuales, no puede ser dada utilizando los fondos del Estado en exclusivo favor de quien ya ocupa la jefatura de la administración pública o, por caso, la jefatura administrativa de un órgano legislativo. La Constitución reformada en el año 1994 ha sido clara al dar a los partidos políticos una suerte de monopolio para canalizar las propuestas electorales $y$, desde esa base, ha decidido asignar recursos para el debate de las ideas políticas. Dice el art. 38 de la Constitución reformada que ella vino a garantizar, entre otras cosas, "la competencia para la postulación de candidatos a cargos públicos electivos, el acceso a la información pública y la difusión de sus ideas". También establece este artículo que el "Estado contribuye al sostenimiento económico de sus actividades" y que "los partidos políticos deberán dar publicidad del origen y destino de sus fondos y patrimonio."

\footnotetext{
${ }^{24}$ Ver informe de la Asociación por los Derechos Civiles, con base en el gasto ejecutado en el año 2007, disponible en www.adc.org.ar.
} 
Vale decir, entonces, que el partido de gobierno, como todos los demás partidos en las proporciones que establece la ley, ya recibe aquella porción de recursos públicos, en dinero o en especie, ${ }^{25}$ mediante los cuales hacer conocer sus ideas y propuestas. ¿Qué justificativo habría para violentar la igualdad ante la ley de cara a los demás partidos políticos, dando carta blanca al partido de gobierno para comprometer, desde el Poder Ejecutivo y sus distintos órganos, pauta publicitaria oficial para sostener discusiones de este tipo?

El serio problema que enfrentará el sistema republicano será todavía mayor si se siguen emitiendo normas que limiten la duración de las campañas. $Y$ no porque no sea racional que la duración de las campañas políticas sea de algún modo acotada para evitar costosas (en recursos y en paciencia) contiendas electorales, sino principalmente porque si, mientras se estatuye una prohibición de este tipo, se habilita al partido de gobierno, a través de la pauta oficial, a seguir haciendo propaganda, se viola la igualdad de base con la que los partidos deben llegar a la contienda. Mordaza para unos, fondos públicos para otros no parece ser una fórmula admisible bajo la Constitución.

$\mathrm{Ni}$ qué hablar, como se espera ahora, cuando además se prohíbe el financiamiento de los partidos políticos por parte de los particulares. ${ }^{26}$ El Estado asumirá un rol que calificará de "irrenunciable", en virtud del propio art. 38 de la Constitución, y se dirá que ello fortalece la democracia. Pero ocurrirá casi con certeza que se asignarán los fondos desde el Poder Ejecutivo con la misma discrecionalidad en las cantidades, en los tiempos o en la forma en que ocurre en tiempo presente, por citar un ejemplo, con la coparticipación federal. ${ }^{27} \mathrm{Y}$, mientras tanto, seguirá el partido de gobierno, el actual o el que venga, disfrutando de la

25 Por ejemplo, en minutos de aire en canales de televisión.

${ }^{26}$ Es importante tener en cuenta que en los Estados Unidos se han producido importantes novedades sobre esta cuestión en los últimos meses. En el caso Citizens United v. Federal Election Commission, del 21 de enero de 2010, la Corte norteamericana afirmó que los topes a los gastos corporativos (o de los sindicatos, que evidentemente cuentan con menor capacidad económica que las grandes empresas) durante las campañas son inválidos. Su argumento principal fue que los límites a los gastos de las corporaciones o de los sindicatos promocionando a un candidato violan el derecho de aquéllos a la libertad de expresión. Resolvió la cuestión permitiendo a las corporaciones gastar de manera ilimitada a la hora de promover a un candidato. Al hacerlo, el alto tribunal invalidó buena parte de la ley federal sobre financiamiento político McCain-Feingold.

27 Durante los últimos meses, las provincias de San Luis, Córdoba, Catamarca, La Pampa y Santa Fe han presentado casos ante la Corte Suprema de Justicia de la Nación vinculados con la asignación y giro de fondos correspondientes a la coparticipación federal. Más recientemente, la Corte ha llegado incluso a citar al Ministro de Economía y al Gobernador de la Provincia de Córdoba para tratar de encontrar una salida sin necesidad de llegar a una decisión formal del tribunal. Todo indica que no le será posible evadir tamaña responsabilidad (ver en Ventura, Adrián, “Boudou y Schiaretti debaten en la Corte por la coparticipación”, La Nación, 14-X-09). 
posibilidad de hacer propaganda a través de la pauta oficial, sufragada bajo el argumento de que se trata de "información pública", de cumplir el mandato del propio art. 38 y del art. $1^{\circ}$ de la Constitución. Nunca palabras tan nobles habrán de ser usadas para objetivos tan bajos.

En el plano federal, existen distintos proyectos de ley en danza ${ }^{28}$ que abordan esta cuestión con mayor o menor fortuna. En ellos se encuentran distintas tipificaciones de lo que puede publicitarse con fondos del Estado. Por ejemplo, se admite la publicidad cuando se trata de: (i) derechos prestacionales que se reconozcan a los ciudadanos; (ii) obligaciones impuestas a los ciudadanos; Consultas públicas; (iii) programas de gobierno respecto de los cuáles los beneficiarios deban ejercer acciones positivas para el otorgamiento de alguna prestación; (iv) condiciones o requerimientos de licitaciones o concursos públicos; (v) medidas adoptadas o a adoptarse en casos de emergencias públicas; o (vi) publicidad relacionada en forma directa con el objeto social de las sociedades controladas por el Estado.

Seguramente surjan de un debate informado y suficiente algunas alternativas adicionales a las antes enumeradas, al mismo que tiempo que matices respecto del contenido de cada una de ellas. Pero es un comienzo. Lo importante aquí es lograr una cada vez más clara diferenciación entre la publicidad de los actos de gobierno (entendida como precondición para la eficacia de ciertos actos ${ }^{29}$ y para el ejercicio de otros derechos) y la propaganda. Lo primero, es mandato constitucional; lo segundo es acción reservada a los partidos políticos a través de los medios con que cuenten de acuerdo a la normativa específica que los regule. Seguramente esta diferenciación, enunciada de este modo, coseche muchas adhesiones. Sin embargo, es preciso reconocer la dificultad que lleva aparejada.

\footnotetext{
${ }^{28}$ (Expte. 0037-D-2009) Proyecto de ley presentado por Silvana Myriam Giudici, con fecha 02.03.2010; (Expte. 4583-D-2009) Proyecto de ley presentado por Federico Pinedo, Paula María Bertol, Esteban José Bullrich, Omar Bruno De Marchi y Enrique Luis Thomas, con fecha 21.09.2009; (Expte. 4328-D-2009) Proyecto de ley presentado por José Ameghino Arbo, José María Roldán, Cesar Alfredo Albrisi y Jorge Luis Albarracín, con fecha 09.09.2009;; (Expte. 3193-D-2009) Proyecto de ley presentado por Laura Gisela Montero, Enrique Luis Thomas, Juan Carlos Scalesi, Daniel Katz y Miguel Angel Giubergia, con fecha 02.07.2009; (Expte. 4048-D2008) Proyecto de ley presentado por María Virginia Linares, Juan Carlos Morán, Horacio Alberto Alcuaz, Fabian Francisco Peralta, Francisco José Ferro, con fecha 29.07.2008; (Expte. 3247-D-2008) Proyecto de ley presentado por Emilio Raul Martínez Garbino con fecha 18/06/2008; (Expte. 1581-D-2008) Proyecto de ley presentado por Fernando Sánchez, Elsa Siria Quiroz, Fernando Adolfo Iglesias, Adrián Pérez, Juan Carlos Moran, Patricia Bullrich, Elisa Beatriz Carca, María Fernanda Reyes, con fecha 18.04.2008; (Expte. 812-D-2008) Proyecto de ley presentado por Federico Pinedo y Paula María Bertol, con fecha 17.03.2008.

29 Si bien no es el objeto de este trabajo, cierto es que la publicidad de los actos de gobierno alcanza, como estándar constitucional, a la necesaria publicación de ciertos actos como condición de eficacia y exigibilidad. Ver en este sentido García Sanz, Agustín A. M., "La publicidad de las normas a través de Internet como estándar mínimo para que sean exigibles", Res Publica Argentina, 2008-3.
} 
Bien podría alguien sostener que dar a conocer la cantidad de escuelas construidas o los kilómetros de rutas pavimentadas bajo una administración determinada es también dar cumplimiento al mandato implícito en el art. $1^{\circ}$ de la Constitución Nacional de dar publicidad a los actos de gobierno. Es que de una apreciación informada acerca del uso de los fondos públicos también puede surgir un mejor ejercicio del sufragio en tanto derecho y obligación, y de controlar a los mandatarios en el ejercicio de las funciones que les han sido encomendadas. Desde otra orilla podría alguien responder que a tal fin bastaría el cartel colocado por el contratista en la obra o una publicación periódica que dé cuenta de la obra de gobierno y a la que se pueda acceder a través de alguna de las tantas modalidades de comunicación que hoy ofrece la tecnología, entre ellas Internet. En este último caso, a lo sumo haría falta que, por los medios tradicionales de publicidad (TV, radio, diarios y revistas), se anuncie que la memoria periódica de gobierno se encuentra disponible en tales y cuales lugares para su consulta. Desde una posición incluso más extrema podría sostenerse que basta a los fines de dar publicidad a los actos de gobierno con el mensaje del Ejecutivo en la apertura de sesiones de su período legislativo y con que la prensa independiente refleje la obra de gobierno, rol que le cabe en las democracias modernas.

Vemos, entonces, cómo la discusión en torno de qué puede o debe ser objeto de publicidad oficial sin correr riesgos de convertirse en propaganda es compleja en sus matices, pero requiere ser tratada y saldada - con respeto de los procedimientos legislativos - pensando alternativas que tengan que ver no sólo con la sustancia sino también con los modos en que esa publicidad es realizada. Es decir, sin ir en desmedro de la publicidad cierta de información relevante acerca de la obra de gobierno, pueden realizarse acciones que de ningún modo se confundan con la propaganda político partidaria que sólo favorece a quien ocasionalmente está a cargo del órgano que realiza dicha publicidad.

\subsection{Los Tiempos: ¿Cuándo puede publicitar el Estado?}

Hasta ahora me he preguntado acerca de la sustancia de la publicidad y de sus confines. Pero una vez respondido el qué, debemos dar el siguiente paso y preguntarnos sobre los modos, empezando por el cuándo. Tal vez la situación que haga más evidente la necesidad de esta pregunta es la de los procesos electorales, como de algún modo adelanté al tratar de diferenciar la publicidad oficial de la propaganda política. 
¿Es realmente lo mismo publicitar con una elección a dos años vista que hacerlo a un mes de las elecciones? ${ }^{30}$ ¿Puede mantenerse la publicidad oficial durante la veda electoral? ¿Es admisible que, mientras se impone un sistema unificado y centralizado de reparto de la pauta para las campañas, el Poder Ejecutivo goce de la más amplia libertad para elegir medios, horarios y cantidades? El no se impone en todos los casos.

No voy a ser novedoso al decir que la inmensa mayoría de la pauta oficial persigue, directa o indirectamente, que el electorado conozca $y$, en función de ello, juzgue favorablemente la obra o las ideas del partido de gobierno en el siguiente turno electoral. Precisamente es por esto que la cantidad de publicidad oficial crece en las cercanías de las elecciones.

Pero a la cuestión de los tiempos electorales, tal vez la más sensible por sus ribetes políticos, deberá sumarse la necesidad de controlar que la publicidad que realmente hace falta sea hecha en tiempo oportuno. Algunas previsiones existen en materia de selección del contratista (aunque eso no significa que se cumplan) pero ¿qué ocurre con las publicaciones relacionadas con prestaciones ofrecidas por el Estado, o con las obligaciones impuestas por el Estado y que pueden, en caso de no ser debidamente dadas a conocer, hacer incurrir en costos y contingencias legales a los particulares?

Indudablemente, la tipificación que se realice de la publicidad oficial será una herramienta fundamental para poder armonizar la necesidad de publicidad con las restricciones y necesidades en materia de tiempos para que dicha publicidad sea efectivamente realizada. Así encontraremos pautas más flexibles para dar a conocer, por ejemplo, fechas de vencimiento de impuestos o de cobro de haberes jubilatorios, que avisos en los que se haga referencia a la obra de gobierno. Hoy, todo forma parte de un colectivo indiferenciado que, como suele ocurrir cuando todo cae en una misma bolsa, termina por favorecer los excesos.

\subsection{Los modos: ¿es necesaria la publicidad que actualmente se realiza en todos los casos?}

Hoy estamos acostumbrados a asociar la publicidad de los actos de gobierno con la pauta publicitaria que el Estado compra en medios gráficos,

\footnotetext{
30 Si la Presidenta de la Argentina, Cristina Fernández de Kirchner, está siendo investigada por presunta violación al artículo 64 del Código Electoral por inaugurar una obra en plena veda electoral. El artículo 64 prohíbe a todo funcionario público inaugurar obras públicas, lanzar o promover planes, "proyectos o programas de alcance colectivo y, en general, la realización de todo acto de gobierno que pueda promover la captación del sufragio." La veda electoral en el momento de la investigación era de tan sólo 7 días. Cabe imaginar que la restricción debiera ser más extensa en materia de publicidad oficial.
} 
en televisión, en radio, en estática o, últimamente, incluso en páginas de Internet de diarios o portales accesibles online. Pero la costumbre no necesariamente debe condicionar las reglas que se definan al momento de dar contorno a la ejecución del gasto en esta sensible materia.

Las nuevas tecnologías ponen a disposición de un creciente número de ciudadanos información que antes dependía, para ser dada a conocer, de cuantiosas inversiones en reproducción gráfica o por otros medios. $Y$ no hablo aquí de meras hipótesis o manifestaciones voluntaristas. En un estudio del año 2009 la UNCTAD, dependiente de las Naciones Unidas, $^{31}$ ha determinado que Argentina es el país con mayor penetración de Internet en la población de toda América Latina. Un 50,32\% de la población ya cuenta con acceso a esta herramienta y la cifra sigue creciendo año a año.

Hoy en día, como es evidente, una página de Internet bien concebida o un canal de comunicación de la Internet $2.0^{32}$ pueden reemplazar eficazmente, incluso superar con creces, al mejor de los diarios en versión papel de circulación nacional como herramienta de comunicación. No sólo porque permite acceder a la información sin deber pagar por un ejemplar o por un acceso concreto a determinada programación, sino también porque supera en herramientas a las modalidades actuales de publicación, dando la posibilidad de sumar elementos multimedia (video, fotos, audio), texto, cuadros, infografías, etc.

En este contexto, y mucho más a medida que avancen los tiempos, Internet puede reemplazar paulatina pero sostenidamente a muchos de los medios tradicionalmente utilizados para dar publicidad a la obra de gobierno en sus diferentes aspectos. De hecho, normativa tan diversa como la de contrataciones públicas, de control comercial agropecuario o de acceso a información impositiva cuenta hoy con previsiones específicas en materia de publicidad por Internet. Como he sostenido con anterioridad, Internet está llamada a convertirse en estándar mínimo exigible para la publicación de las normas, de modo de hacerlas exigibles, superando incluso al Boletín Oficial..$^{33}$

De este modo y como adelantara párrafos más arriba, podrían destinarse dineros públicos a instalar en la población las direcciones

\footnotetext{
31 Ver en http://www.unctad.org/Templates/Webflyer.asp?doclD=12271\&intltemID=1528\&lang=3.

32 Se cuentan por decenas las experiencias de gobiernos de todo orden utilizando Facebook o Twitter para establecer canales de comunicación con la ciudadanía. Por todos, ver http://twitter.com/gcba/.

33 Ver García Sanz, Agustín A. M., "La publicidad de las normas...., op. cit.
} 
de Internet de los portales en los que la publicidad oficial se encuentra debidamente sistematizada y detallada, antes que realizar toda la publicidad en forma directa a través de los medios tradicionales. Bastará con poner a disposición del público terminales de acceso gratuito en oficinas estatales o en instituciones asociadas por vía de convenios, incluso con asistencia de personal del Estado para quienes tengan dificultades de acceso, para atender las necesidades de una transición hacia los medios electrónicos que parece irreversible.

La adopción de políticas de largo plazo como la aquí propuesta no sólo redundará en una más adecuada asignación de recursos y en una más eficaz comunicación de los contenidos que el Estado debe hacer públicos, sino también en una paulatina liberación de los medios de comunicación de la dependencia del Estado que necesariamente viene asociada a la incidencia de la pauta estatal en su flujo de ingresos. Lo que hoy puede lucir como un perjuicio para su rentabilidad presente, será garantía de libertad de expresión en tiempo futuro.

2.6 Control de pautas y ejecución del gasto: ¿quién le pone el cascabel al gato?

Hoy por hoy la ejecución del gasto en materia de publicidad oficial está hoy confiada a las cabezas de los órganos administradores, sea que se trate del Poder Ejecutivo o de los restantes poderes; sea que se trate de la Nación, o de las Provincias y Municipios. Esta es la regla. Es que, en un marco de discrecionalidad casi absoluta, los incentivos para que las autoridades del poder $\mathrm{u}$ órgano administrador lleven adelante la tarea de asignar la pauta son demasiado grandes.

Por el contrario, cuanto más claras sean las reglas para la asignación de estos recursos, cuanto más concretos sean los contornos del qué, del cómo y del cuándo que vengo de analizar, más fácil será buscar alternativas orgánicas para el control de cumplimiento de esas pautas y para la ejecución del gasto en esta materia.

Ciertamente, no parece razonable que quien ejerza el control sobre estos parámetros sea, en solitario, el mismo que podría beneficiarse con los efectos de esa publicidad. No puede una agencia de noticias oficial dependiente del Pode Ejecutivo, tal lo que ocurre en el caso de la Nación, ser confiada con el rol de controlar los abusos en los que pudiera incurrir el propio poder administrador a la luz de los estándares analizados. 
No es razonable desde la lógica de frenos y contrapesos de nuestro sistema republicano de gobierno.

Debiera, entonces, analizarse seriamente la posibilidad de crear agencias $^{34}$ exentas del control omnímodo de uno solo de los poderes del Estado, máxime teniendo en cuenta que los tres poderes deben realizar publicidad oficial. Luce más razonable que exista un órgano con integración plural de los distintos poderes que ejecutan partidas destinadas a la publicidad oficial o, al menos, un órgano creado e integrado en forma representativa (no sólo por cuestiones de diversidad partidaria, sino también territorial) ${ }^{35}$ por el Congreso Nacional que permita balancear el poder unipersonal del Ejecutivo (el más relevante a los efectos de este análisis) o de los administradores de los otros poderes del Estado. Sólo de este modo se podrá confiar al órgano que debe ejecutar la pauta que realice un control efectivo, ex ante, de los parámetros fijados por la ley que eventualmente se dicte.

\subsection{Contratación: ¿Cómo debe contratarse la publicidad?}

La contratación de la pauta oficial aparece hoy signada por la discrecionalidad en todos sus aspectos. No sólo en torno de cuáles son los medios destinatarios de esa pauta, sino también en torno del procedimiento que debe seguirse para concretar la contratación. En el plano federal esta anomia es evidente.

No es posible que una caja chica de $\$ 500$ ( $R \$ 238$ ) tenga un procedimiento claro para su aprobación y que no lo tenga la ejecución de los más de $\$ 600$ millones ( $\$ \$ 286$ millones) que gastará el Estado nacional en materia de publicidad durante este año. Es demasiado el margen para el error, en el mejor de los casos. Se impone la necesidad de contar, al tiempo de regular esta materia, con un procedimiento claro y transparente para la contratación de los espacios de publicidad, clarificando adecuadamente el rol que pueden jugar los intermediarios o mayoristas de espacios de publicidad.

${ }^{34}$ Confieso que no soy afecto a la creación de nuevas dependencias públicas, como criterio general. Bastantes organismos existen ya sin prestar adecuados servicios a los contribuyentes. Sin embargo, entiendo que los organismos o agencias de control existentes, en tanto mantengan potestades de contralor ex post facto sin responsabilidad en la ejecución presupuestaria en tiempo presente, no resuelven la cuestión que aquí planteo.

35 Porque no debe perderse de vista que, al asignar en forma discrecional y desproporcionada la pauta, puede terminarse beneficiando no sólo a medios determinados sin que ello reconozca asidero en su penetración en el mercado, sino también a medios de centros urbanos de mayor relevancia política (Capital Federal y GBA, por ejemplo) en detrimento de medios igualmente relevantes del interior del país. 
2.8 ¿Hace falta una norma?

Cada uno de los temas reseñados abre un sinfín de alternativas en materia de herramientas de gestión y control. Pero sin perjuicio de los contenidos en concreto, lo que entiendo que no puede cuestionarse seriamente a esta altura es la necesidad de que exista una norma que empiece a definir criterios y estructuras orgánicas que permitan resolver un problema que crece a la velocidad del gasto en pauta publicitaria oficial. ${ }^{36}$

Existen distintos proyectos esperando a ser tratados por el Congreso nacional, como ya he adelantado. Tal vez tengan una primera oportunidad de ser debatidos a partir del reciente cambio de mayorías parlamentarias, aunque ello no signifique que sean convertidos en ley. Mientras la ley no exista, no existirán los órganos con competencia para controlar y ejecutar el gasto en pauta publicitaria del Estado, ni existirán los criterios a los que deba ajustarse el gasto, a los que puedan acudir los jueces en el control judicial en el caso concreto.

Pero eso no significa que el gasto quede exento de todo control en tiempo presente. El gasto en publicidad debe ser controlado por los jueces, tanto más ante la ausencia de una norma que otorgue competencia primaria a un órgano suficientemente independiente para dirimir estas cuestiones. A estas cuestiones dedicaré el acápite siguiente.

3 El rol de la Justicia ante la falta de un marco legal adecuado

Así como se han fijado estándares respecto de los confines de la discrecionalidad en el citado caso Perfil, en Editorial Río Negro c. Provincia de Neuquén y en Radiodifusora Pampeana S.A. c. Provincia de La Pampa, cobrará importancia la discusión respecto de los confines de la sustancia y los modos de publicitar. Desde ya, será más difícil la tarea judicial ante la ausencia de criterios fijados legislativamente, pero esa barrera puede ser superada como bien lo hizo la Corte en Halabi, ${ }^{37}$ al sostener que la falta de régimen normativo no es excusa para la inacción judicial. La Constitución Nacional brinda hoy, sin necesidad de mayores precisio-

\footnotetext{
36 Por citar un ejemplo, el Estado federal gastó a lo largo de 2008, ejercicio respecto del cual ya están disponibles los datos cerrados, $\$ 396.307 .367$, es decir, un $756,54 \%$ más que en 2003 . Como he señalado supra, también se han detectado crecimientos exponenciales en el gasto en publicidad en otras administraciones, como es el caso del Gobierno de la Ciudad de Buenos Aires. No estamos, repito, ante una cuestión que admita cargar las tintas sobre un partido político en forma aislada. Es un mal endémico.

${ }^{37}$ Fallos 332:111, especialmente Considerando 12 del voto mayoritario.
} 
nes normativas, herramientas suficientes para dar por tierra con la gran mayoría de la propaganda política que hoy se disfraza de publicidad oficial.

En este contexto, pasaremos de una discusión limitada al Derecho a la Igualdad - Derecho de Acceso a la Información - Derecho a la libertad de Expresión, por cierto loable, a una discusión más rica, en la que entrarán en escena la División de Poderes y Sistema Republicano, el Principio de Legalidad, el Principio de Razonabilidad, el Sistema Presupuestario y el Sistema de Partidos Políticos.

Se avecinan nuevos desafíos para la Justicia en el control de la pauta publicitaria. Se están dando importantes pasos en materia de control de la discrecionalidad en la asignación de fondos. ¿Tendremos la suerte de festejar también decisiones sobre algunos de los otros puntos tratados en esta breve presentación? La cercanía del debate electoral presidencial permite imaginar las condiciones para que este debate se presente. Tal vez una acción de amparo con medida cautelar ${ }^{38}$ sea el punto de partida de esta segunda discusión, todavía pendiente, mientras llega el tiempo de políticas de Estado en la materia.

La publicidad de una determinada agenda política o ideológica, de las bondades de tal o cual proyecto de ley o de los méritos de una administración en particular, por loables que sean los objetivos perseguidos, no puede ser sufragada con dineros provenientes de los impuestos, salvo que ello ocurra en la estricta medida de los aportes que reciben los partidos políticos. Y si de lograr ese objetivo se trata, el manejo de fondos para la publicidad que deban hacer todos los poderes del Estado (no sólo el Poder Ejecutivo) debería estar a cargo de un órgano plural e independiente de los vientos políticos de turno, con facultad para revisar que los contenidos de la publicidad propuesta se ajusten a estas pautas. ¿Serán estos los nuevos confines de la discusión? ¿Podrá debatirse a partir de ahora, con las bases que la Justicia está afianzando, sobre la sustancia de la publicidad oficial y no ya sólo de la cantidad o las formas? El tiempo lo dirá. Baste por el momento proponer la discusión.

\footnotetext{
${ }^{38}$ Como el presentado por Beltrán Gambier en el año 1999 en ocasión de la resonante campaña "Menem lo hizo", que mereciera el dictado de una medida cautelar por la Justicia de primera instancia, confirmada por la Sala II de la Cámara Nacional de Apelaciones en lo Contencioso Administrativo Federal (ver Gambier, Beltrán c. Poder Ejecutivo Nacional, La Ley 1999-E, 624).
} 
Judicial Control of Discretion in the Allocation of Official Advertising in Argentina

Abstract: The article discusses the issue of judicial control of discretion in the allocation of official advertising in Argentina, from the study of a decision from Room IV of the Appeals National Chamber of the Federal Administrative Justice.

Key words: Judicial control. Discretion. Allocation of official advertising. Argentine Republic.

Informação bibliográfica deste texto, conforme a NBR 6023:2002 da Associação Brasileira de Normas Técnicas (ABNT):

GARCÍA SANZ, Agustín A. M. El control judicial de la discrecionalidad en la asignación de pautas publicitarias del Estado en la Argentina. A\&C - Revista de Direito Administrativo \& Constitucional, Belo Horizonte, ano 10, n. 42, p. 69-86, out./dez. 2010.

Recebido em: 03.03.10

Aprovado em: 29.11.10 